\title{
Primary pulmonary hypertension, Castleman's disease and human herpesvirus-8
}

\author{
T.M. Bull*, C.D. Cool ${ }^{\#}$, A.E. Serls\#, P.R. Rai", J. Parr", J.M. Neid", M.W. Geraci*, \\ T.B. Campbell", N.F. Voelkel*, D.B. Badesch*
}

Primary pulmonary hypertension, Castleman's disease and human herpesvirus-8. T.M. Bull, C.D. Cool, A.E. Serls, P.R. Rai, J. Parr, J.M. Neid, M.W. Geraci, T.B. Campbell, N.F. Voelkel, D.B. Badesch. C) ERS Journals Ltd 2003.

ABSTRACT: Primary pulmonary hypertension (PPH) and Castleman's disease (CD) are rare conditions infrequently encountered in clinical practice.

In this paper, two patients diagnosed with both of these diseases are reported. The authors speculate that rather than being a chance occurrence, these conditions are linked by a common angio-proliferative mechanism. Therefore, an association between infection with the human herpesvirus-8 and the diseases of PPH and CD was sought.

Evidence of human herpesvirus-8 infection was found in the lung tissue and, specifically, in the plexiform lesions from one of the patients.

Eur Respir J 2003; 22: 403-407.
* Dept of Medicine, Division of Pulmonary and Critical Care Medicine, Pulmonary Hypertension Center, "Dept of Pathology and Division of Infectious Disease, University of Colorado Health Sciences Center, Denver, CO, USA.

Correspondence: T.M. Bull, Division of Pulmonary Sciences and Critical Care Medicine, University of Colorado School of Medicine, Box C-272, 4200 East Ninth Ave, Denver, CO 80262, USA.

Fax: 13033155632

E-mail: Todd.Bull@uchsc.edu

Keywords: Endothelial cell, human herpesvirus8 , plexiform lesion, primary pulmonary hypertension

Received: January 192003

Accepted after revision: April 172003
Primary $(\mathrm{P})$ or unexplained pulmonary hypertension $(\mathrm{PH})$ is a poorly understood disease with devastating clinical consequences. Patients with PPH develop a marked and unexplained elevation of pulmonary artery pressure that often results in right heart failure and death [1].

The plexiform lesion is one of the characteristic histopathological lesions of PPH. Recent investigation has emphasised the important role of endothelial cells (ECs) in the disease process of severe PH [2]. The plexiform lesion itself is composed of a disorganised "tumour like" proliferation of endothelial cells. In patients with PPH the ECs that compose the plexiform lesion are monoclonal in origin while in patients with secondary PH they are polyclonal $[3,4]$. The ECs of the plexiform lesions in PPH patients possess microsatellite instability and abnormal expression of growth and apoptosis control genes similar to some forms of neoplasia [5].

Castleman's disease (CD) is a highly heterogeneous clinicalpathological entity belonging to the lymphoproliferative disorders [6]. Histologically CD is classified into two major types according to pathological findings: 1) the hyalinevascular type with small hyaline-vascular follicles and interfollicular capillary proliferation; and 2) the plasma-cell type characterised by a massive accumulation of polyclonal plasma-cells in the interfollicular region. There is also a third, mixed variant, with features of both hyaline vascular and plasma-cell types [6, 7]. Clinically, CD can be classified into either localised or systemic forms. The usual presentation for localised disease is a single enlarged lymph node or widened mediastinum. The systemic form of the disease, also referred to as multicentric CD (MCD), is characterised by diffuse lymphadenopathy, hepatosplenomegaly and constitutional symptoms. Localised $\mathrm{CD}$ of the hyaline vascular type is usually asymptomatic, whereas patients with the plasma cell variant often have systemic manifestations. Patients with MCD have significant lymphadenopathy and an aggressive, sometimes fatal, clinical course [6]. Although the aetiology of $\mathrm{CD}$ is unknown, levels of cytokines such as interleukin (IL)-1, -6 and tumour necrosis factor- $\beta$ are increased in the serum of patients with this disease [8]. Others [7] have reported an increased expression of vascular endothelial growth factor (VEGF) in the serum and lymph nodes of patients with CD. VEGF is a specific mitogen for vascular endothelial cells and plays a central role in angiogenesis. Nishi and MARUYAMA [7] hypothesised that the marked vascular proliferation in the interfollicular space seen in this disease process was related to the elevated VEGF levels. Interestingly, it has been documented that patients with PPH have increased levels of VEGF in their serum and the plexiform lesions of PPH express high levels of this growth factor and its receptor $[9,10]$. It has been hypothesised that the increased serum VEGF levels found in patients with PPH serve as a stimulus for endothelial cell proliferation, perhaps contributing to the pathobiology of the disease [3].

Recently, human herpesvirus (HHV)-8 has been associated with MCD and a viral homologue of IL-6 (vIL-6) encoded by HHV-8 has been demonstrated to induce VEGF expression [7, 11]. Viral infection with agents such as human immunodeficiency virus type-1 (HIV-1) is associated with the development of severe $\mathrm{PH}$, indistinguishable clinically or pathologically from PPH. Although a direct causal relationship between $\mathrm{PH}$ and a viral infection has not been established, such a relationship is strongly suspected [12, 13]. 
POEMS (polyneuropathy, organomegaly, endocrinopathy, monoclonal gammopathy and skin changes) syndrome is a rare variant of plasma cell dyscrasia with multiple systemic manifestations [14]. POEMS syndrome has been associated with both MCD and with HHV-8 infection [11, 15]. Intriguingly, severe $\mathrm{PH}$, with histology similar to that found in PPH (plexiform lesions and in situ micro thrombosis) has been reported in patients with POEMS syndrome [16]. It has also been noted that patients with POEMS syndrome and $\mathrm{PH}$ have elevated serum levels of VEGF [16].

In this paper, two patients diagnosed with both PPH and MCD are reported. An evaluation for an association between $\mathrm{PPH}, \mathrm{CD}$ and HHV-8 was undertaken in these two patients.

\section{Case 1}

A 34-yr-old Hispanic female (patient 1) presented with the chief complaint of a nonproductive cough, increasing dyspnoea and new-onset lower extremity oedema. The patient denied a previous history of deep venous thrombosis, pulmonary embolism, exposure to anorexic agents or intravenous drug use. An HIV test was negative. There was no evidence of a connective tissue disease on physical exam. An accentuated pulmonic component of the second heart sound was audible but lung sounds were normal. A chest radiograph demonstrated prominent pulmonary arteries and right ventricular hypertrophy. The patient's electrocardiogram was consistent with right ventricular hypertrophy. An echocardiogram demonstrated normal left ventricular systolic function. The right atrium and right ventricle were dilated and severe tricuspid regurgitation was noted. The pulmonary artery systolic pressure was estimated to be $60-65 \mathrm{mmHg}$ plus right atrial pressure. A ventilation perfusion scan was interpreted as low probability for pulmonary embolism. A high resolution computed tomography (CT) scan of the patients chest demonstrated normal lung parenchyma but enlargement of the pulmonary arteries. Pulmonary function tests demonstrated mild airflow limitation and a decreased carbon dioxide diffusing capacity of the lung ( $D \mathrm{~L}, \mathrm{CO}, 58 \%)(D \mathrm{~L}, \mathrm{CO} / \mathrm{alveolar}$ volume ( $V A) 72 \%$ ). A sleep study demonstrated no evidence of obstructive sleep apnoea. Blood serology for connective tissue disease demonstrated a positive antinuclear antibody of 1:256 with a speckled pattern. There was no other evidence of collagen vascular disease. Other markers of connective tissue disease were normal. Right heart catheterisation with a vasodilator trial (table 1) did not demonstrate a "significant" acute response to the vasodilator prostacyclin. The patient was diagnosed with severe, unexplained (P) PH and continuous $i$.v. prostacyclin therapy was initiated. The patient also began evaluation for lung transplantation, during which a pelvic and

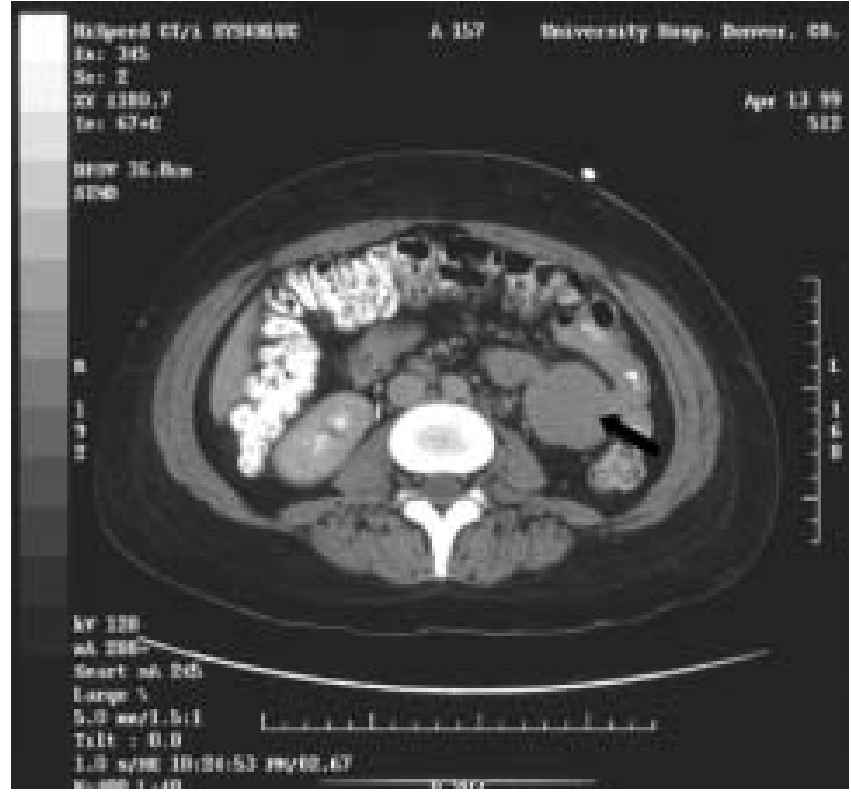

Fig. 1.-Computed tomographic scan of the abdomen of patient 1, demonstrating mass lesion (arrow).

abdominal CT scan revealed a $4.0 \times 6.0 \times 3.5 \mathrm{~cm}$ abdominal mass (fig. 1). The patient underwent laparotomy with removal of the mass, seemingly in its entirety. Histological evaluation demonstrated the plasma-cell variant of CD (fig. 2). The patient was initially followed conservatively, but in the ensuing months was noted to have increased lymphadenopathy and the development of weight loss and night sweats. The patient was given a trial of cytoxan and decadron without noticeable improvement. The patient was then treated with four weekly doses of rituxan. This resulted in a complete resolution of all lymphandenopathy and "B" type symptoms. The patient was judged to be in complete remission from $\mathrm{CD}$ although severe PH persisted.

Three years after the diagnosis of PPH and the initiation of continuously infused prostacyclin, the patient was admitted for increasing shortness of breath, hypoxia and rapidly increasing lower extremity oedema. Careful diuresis was attempted but the patient suffered a bradycardic arrest during the hospitalisation. Aggressive attempts at resuscitation were unsuccessful and the patient expired 5 days after admission. The cause of death was determined to be severe $\mathrm{PH}$ and right heart failure. At autopsy no residual evidence of $C D$ was uncovered but examination of the lung tissue confirmed the presence of plexogenic pulmonary arteriopathy (fig. 3).

Table 1.-Cardiac catheterisation results from patients 1 and 2 at baseline and at maximum infused dose of prostacyclin (max. $\mathrm{PGI}_{2}$ )

\begin{tabular}{|c|c|c|c|c|c|}
\hline & \multicolumn{2}{|c|}{ Patient 1} & \multicolumn{2}{|c|}{ Patient 2} & \multirow{2}{*}{$\frac{\text { Patient } 2 \text { repeat }^{\#}}{\text { Baseline }}$} \\
\hline & Baseline & Max. $\mathrm{PGI}_{2}$ & Baseline & Max. $\mathrm{PGI}_{2}$ & \\
\hline$P$ pcw $\mathrm{mmHg}$ & 8 & 8 & 13 & 17 & 10 \\
\hline$P$ pa pressure $\mathrm{S} / \mathrm{D} / \mathrm{m} \mathrm{mmHg}$ & $94 / 38 / 58$ & $103 / 41 / 63$ & $71 / 32 / 48$ & $60 / 29 / 41$ & $39 / 18 / 28$ \\
\hline Pra pressure mean $\mathrm{mmHg}$ & 11 & 16 & 20 & 18 & 9 \\
\hline Systemic BP S/D/m mmHg & $109 / 69 / 79$ & $103 / 71 / 79$ & $111 / 66 / 75$ & $102 / 57 / 73$ & $110 / 68 / 76$ \\
\hline Cardiac output $\mathrm{L} \cdot \mathrm{min}^{-1}$ & 3.6 & 4.2 & 6.6 & 7.33 & 7.3 \\
\hline PVR dyne $\cdot \mathrm{s}^{-1} \cdot \mathrm{cm}^{-5}$ & 1111 & 1048 & 424 & 263 & 197 \\
\hline Shunt & \multicolumn{2}{|c|}{ No evidence } & \multicolumn{2}{|c|}{ No evidence } & \\
\hline
\end{tabular}

Ppcw: pulmonary capillary wedge pressure; Ppa: pulmonary artery pressure (systolic/ diastolic/mean); Pra: right atrial pressure; BP: blood pressure (systolic/diastolic/mean); PVR: pulmonary vascular resistance; ${ }^{\#}$ : repeat cardiac catheterisation on patient 2 after 8 months of bosentan and rituxen therapy. 


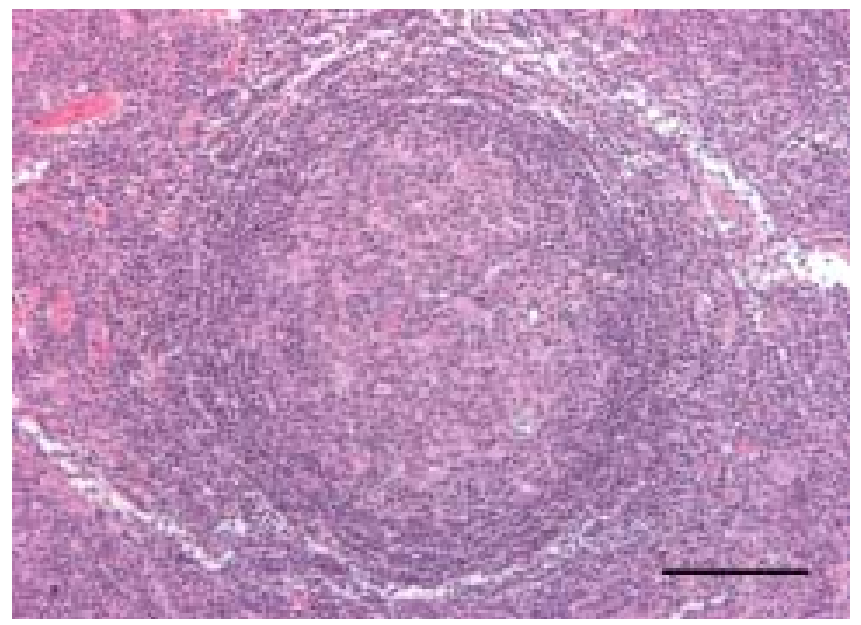

Fig. 2.-Lymph node with evidence of Castleman's disease from patient 1 . Scale bar $=100 \mu \mathrm{m}$.

\section{Case 2}

A 44-yr-old Caucasian male (patient 2) was referred for evaluation of progressively worsening lower extremity oedema and increasing dyspnoea. The patient denied a history of appetite suppressant use or connective tissue disease. Blood serology for HIV was negative. The patient had a history of obstructive sleep apnoea, which was being treated successfully with continuous positive airway pressure. The patient denied any previous history of deep venous thrombosis or pulmonary embolism. Physical exam demonstrated a prominent second heart sound and an III/VI systolic murmur loudest at the left upper sternal border. The patient was also noted to have $2+$ bilateral lower extremity oedema and both anterior-cervical and inguinal lymphandenopathy. A chest radiograph demonstrated enlargement of the cardiac silhouette. An echocardiogram demonstrated normal left ventricular wall thickness and function. The right atrium was dilated and there was moderate tricuspid regurgitation. The right ventricular systolic pressure was estimated to be $45 \mathrm{mmHg}$. A ventilation-perfusion scan was interpreted as low probability for pulmonary embolus. Bilateral lower extremity ultrasound demonstrated no evidence of deep vein thrombosis. Pulmonary function tests demonstrated normal spirometry, mildly decreased lung volumes thought to be

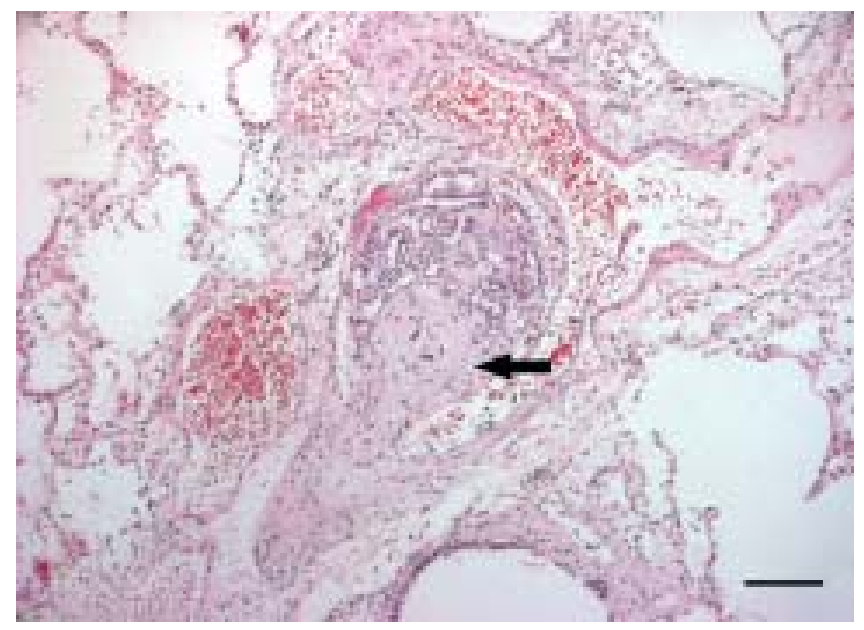

Fig. 3. - Plexiform lesion from patient 1 (arrow). Scale bar $=100 \mu \mathrm{m}$. related to the patient's body habitus and a decreased $D \mathrm{~L}, \mathrm{CO}$ (47\%) (DL,CO/VA 72\%). Physical exam and serology did not reveal evidence of a connective tissue disease.

The patient underwent right heart catheterisation with a trial of the vasodilator prostacyclin (table 1). The diagnosis of unexplained (P) $\mathrm{PH}$ was made. The patient demonstrated a significant response to prostacyclin with a $15 \%$ decrease in mean pulmonary artery pressure $(\mathrm{Ppa})$ and $>25 \%$ decrease in pulmonary vascular resistance. During the same hospitalisation the patient was noted to have nocturnal fevers and night sweats. Physical exam demonstrated anterior cervical and supraclavicular adenopathy. A CT scan of the neck, chest and abdomen confirmed significant supraclavicular, pre-tracheal and bilateral inguinal adenopathy. The patient underwent excision of a right supraclavicular lymph node. The biopsy demonstrated a mixed variant of CD (fig. 4). The patient was initially started on a calcium channel blocker for treatment of $\mathrm{PH}$, however, the patient was intolerant of this medication and was changed to the endothelin antagonist bosentan. Other treatment consisted of four weekly doses of rituxan for CD. Eight months after starting these medications the patient's lymphandenopathy resolved and $P$ pa was significantly decreased.

Evaluation for an association between PPH, CD and HHV-8 was undertaken in these two patients.

\section{Materials and methods}

\section{Specimens}

The specimens were obtained from lymph node and lung autopsy samples from patient 1 and from a lymph node biopsy of patient 2. Positive controls for polymerase chain reaction (PCR) and immunohistochemistry were selected from other patient specimens previously diagnosed with Kaposi's sarcoma. Negative controls were from lung and lymph node sections of patients with unrelated diagnoses. All samples were prepared from formalin-fixed, paraffinembedded tissue sections.

\section{Immunohistochemistry}

The primary antibody used was a rat immunoglobulin G1 to open reading frame (ORF) 73 (Advanced Biotechnologies Inc, Columbia, MD, USA). Biotinylated secondary antibodies were from the Vectastain Elite Rat ABC Kit

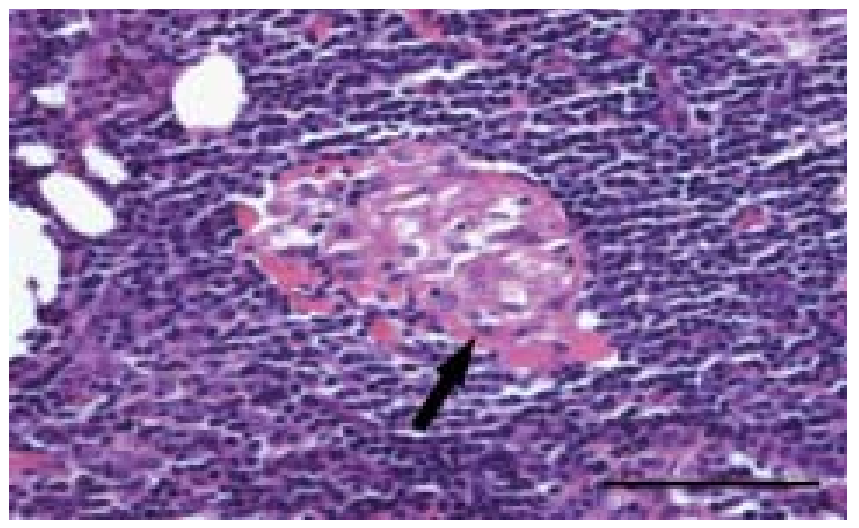

Fig. 4.-Lymph node from patient 2 demonstrating a regressively transformed germinal center. Hyalinised capillaries are evident (arrow). Scale bar $=100 \mu \mathrm{m}$. 
(Vectastain, Burlingame, CA, USA) as per the manufacturer's recommendations.

\section{Polymerase chain reaction}

PCR was performed on lung and lymph node tissue using the primers for ORF 72 (vCyclin) and the protocol as described by PAN et al. [17]. The primers used were: forward (5'-CGCCTGTAGAACGGAAACAT- $\left.3^{\prime}\right)$; and reverse $\left(5^{\prime}-\right.$ TTGCCCGCCTCTATTATCAG-3') with a 138 base pair product. The PCR reaction mixture consisted of $25 \mathrm{mM}$ $\mathrm{MgCl}_{2}, 10 \mathrm{mM}$ dNTPs, $1 \mu \mathrm{M}$ of each primer, $5 \mathrm{U} \cdot \mathrm{mL}^{-1} \mathrm{Taq}$ polymerase (Boehringer Mannheim, Indianapolis, IN, USA), in a total volume of $25 \mu \mathrm{L}$. Amplification was performed in an oil-free thermocycler (Model GeneAmp 2400; Perkin Elmer, Foster City, CA, USA). The thermocycler conditions were $94^{\circ} \mathrm{C}$ for $2 \mathrm{~min}, 94^{\circ} \mathrm{C}$ for $1 \mathrm{~min}, 58^{\circ} \mathrm{C}$ for $1 \mathrm{~min}$ and $72^{\circ} \mathrm{C}$ for $1 \mathrm{~min}$ for 35 cycles, then $72^{\circ} \mathrm{C}$ for $5 \mathrm{~min}$.

PCR was performed on serum samples of patient 2, evaluating the HHV-8 minor capsid (ORF 26), from nucleotides 47311 to 47384 of the HHV-8 genome, as
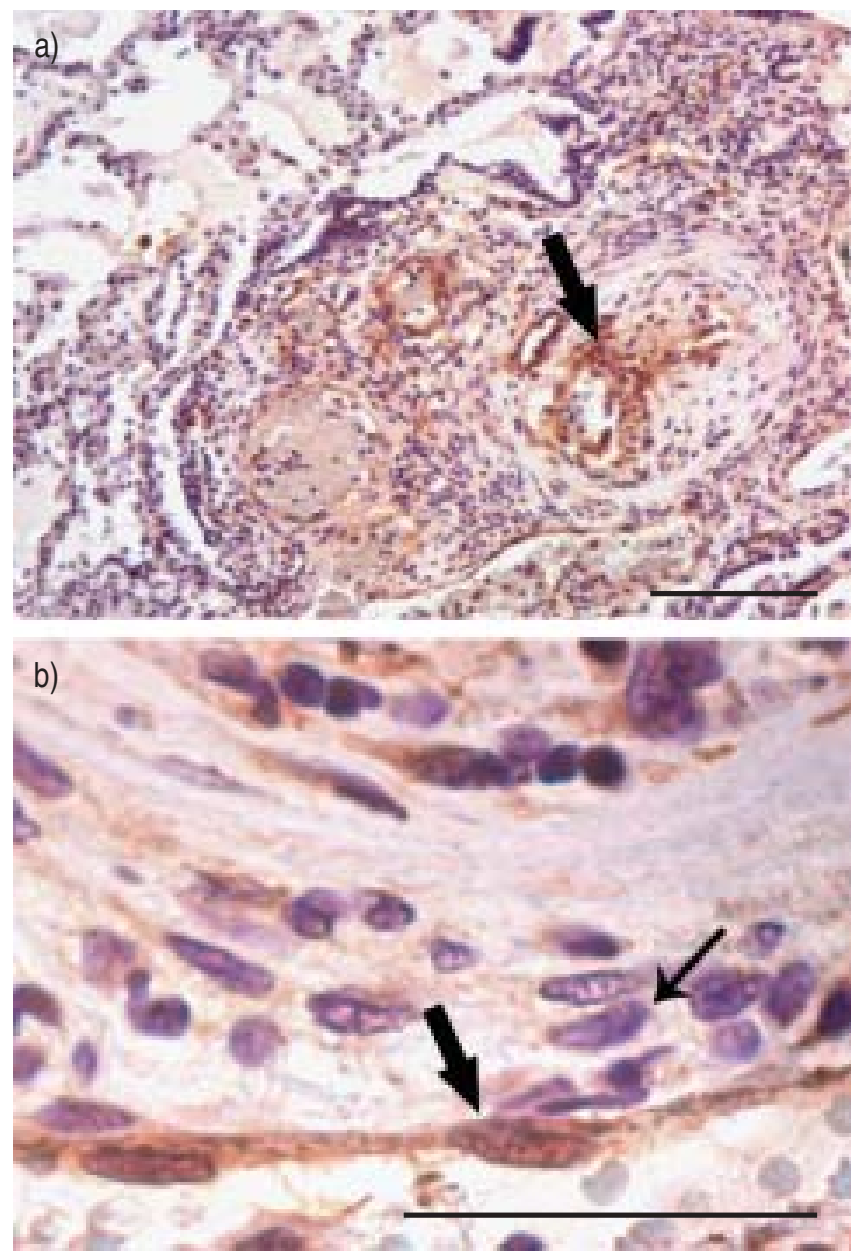

Fig. 5.-Tissue section from patient 1 (lung) demonstrating positive staining for human herpesvirus (HHV)-8. a) The cells that stained positive for HHV-8 were predominantly endothelial cells and lymphocytes located within and around the plexiform lesion (large arrow). Scale bar $=100 \mu \mathrm{m}$. b) Positive staining of endothelial cells (large arrow). Note the negative staining of the smooth muscle cells (small arrow). Lymph nodes from patients 1 and 2 were negative for HHV-8 by immunohistochemistry (data not shown). Kaposi's Sarcoma lesions served as positive controls (data not shown). Scale bar $=50 \mu \mathrm{m}$. described previously by White and CAMPBell [18]. Deoxyribonucleic acid (DNA) sequencing was performed in the University of Colorado School of Medicine DNA sequencing and analysis core using ABI Prism kits from Applied Biosystems (Foster City, CA, USA).

\section{Enzyme-linked immunosorbent assay}

The VEGF level present in the serum of patient 2 was quantified by enzyme-linked immunosorbent assay (ELISA) (R\&D Systems Inc., Minneapolis, MN, USA).

\section{Indirect immunofluorescense assay}

The presence of antibodies to Kaposi's sarcoma-associated herpesvirus latent nuclear antigens (LANA) was determined by immunofluorescent assay (IFA) with latency infected BCP-1 cells as previously described [19]

\section{Results}

The immunohistochemistry of the lung sections from patient 1 was positive for HHV-8 (fig. 5). The lymph node sections from patients 1 and 2 were negative for HHV-8 by staining (data not shown)

The PCR of lung tissue from patient 1 was positive for HHV-8 using the primers for ORF 72. The PCR product was sequenced and was shown to be $97 \%$ homologous to the expected product for ORF 72 (data not shown). The lymph nodes from patients 1 and 2 were negative by PCR for HHV-8 (fig. 6).

A serum sample from patient 2 was negative for HHV-8 by PCR for the minor capsid (ORF 26). The amount of VEGF present in his peripheral blood as measured by ELISA was within normal limits $\left(118 \mathrm{pg} \cdot \mathrm{mL}^{-1}\right)$. Serology from patient 2 was negative for HHV-8 by IFA.

\section{Discussion}

PPH and CD are both rare pathological conditions. The occurrence of both diseases in two different patients is remarkable and raises interesting questions regarding pathogenesis. Both CD and PPH have been associated with high serum VEGF levels and both diseases have been described as angioproliferative and vasculoproliferative processes [3, 7].

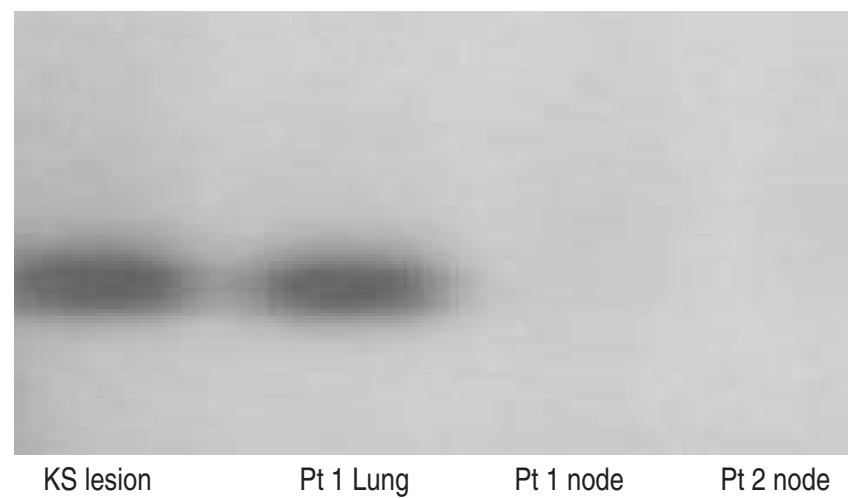

Fig. 6. - Polymerase chain reaction for human herpesvirus (HHV)-8 (ORF72). Lane 1 is a positive control using a Kaposi's sarcoma (KS) lesion. Lane 2 is from lung tissue of patient 1 ( $\mathrm{Pt} 1 \mathrm{lung}$ ) (positive). Lane 3 is lymph node tissue from patient 1 ( $\mathrm{Pt} 2$ node) (negative) Lane 4 is lymph node tissue from patient 2 ( $\mathrm{Pt} 2$ node) (negative). 
The current authors hypothesised that HHV-8 might be a common inciting agent for both diseases in the two patients presented here. There was immunohistochemical evidence of HHV-8 infection in the lung tissue of patient 1, although there was no evidence in the lymph nodes of either patient. Importantly, the HHV-8 staining was noted in the endothelial cells in and around the plexiform lesion while other cells, such as those of smooth muscle, were negative. HHV-8 commonly infects endothelial cells [20]. There was also PCR evidence of HHV-8 in the lung tissue of patient 1, but again not in the lymph nodes of either patient. In the serum of patient 2 , there was no PCR evidence of active HHV-8 infection, the VEGF levels were not elevated and there was no positive serology for HHV-8 (these tests could not be performed on patient 1 as the patient had expired by this time). However, it should be noted that the serum HHV-8 PCR and VEGF levels were drawn late in the patient's course and after the initiation of treatment with resolution of the patient's lymphandenopathy and significant improvement of PH. It should also be noted that not all patients with HHV-8 infection have positive serology. The reported sensitivity for HHV-8 LANA seropositivity in patients with Kaposi's sarcoma is only $70-80 \%$ [21, 22].

The potential role of HHV-8 in the development of $\mathrm{PH}$ is intriguing. The authors speculate that HHV-8 might induce the production of VEGF in the infected host via a viral homologue of IL- 6 and this might result in an angiogenic cascade, as proposed initially by NISHI and MARUYAMA [7]. If the HHV-8 infection was local, for example in the lungs or the lymph nodes, this could explain the organ-specific features of both PPH and CD. The current authors were unable to demonstrate an elevated VEGF level in patient 2, but elevated VEGF levels in PPH and CD have been reported previously $[7,9]$.

It has been speculated that primary pulmonary hypertension may occur in individuals with a genetic predisposition for the disease who are then exposed to a "second hit" resulting in changes in the proliferation of pulmonary vascular endothelial cells and the development of severe pulmonary hypertension. Here, the authors suggest that infection with human herpesvirus- 8 may serve as a second hit in some cases. This hypothesis now needs to be tested in a larger cohort of patients.

\section{References}

1. Archer S, Rich S. Primary pulmonary hypertension: a vascular biology and translational research "work in progress". Circulation 2000; 102: 2781-2791.

2. Tuder RM, Cool CD, Yeager M, Taraseviciene-Stewart L, Bull TM, Voelkel NF. The pathobiology of pulmonary hypertension. Endothelium. Clin Chest Med 2001; 22: 405- 418.

3. Voelkel NF, Cool C, Lee SD, Wright L, Geraci MW, Tuder RM. Primary pulmonary hypertension between inflammation and cancer. Chest 1998; 114: 225S-230S.

4. Lee SD, Shroyer KR, Markham NE, Cool CD, Voelkel NF, Tuder RM. Monoclonal endothelial cell proliferation is present in primary but not secondary pulmonary hypertension. J Clin Invest 1998; 101: 927-934.

5. Yeager ME, Halley GR, Golpon HA, Voelkel NF, Tuder RM. Microsatellite instability of endothelial cell growth and apoptosis genes within plexiform lesions in primary pulmonary hypertension. Circ Res 2001; 88: E2-E11.
6. Herrada J, Cabanillas F, Rice L, Manning J, Pugh W. The clinical behavior of localized and multicentric Castleman disease. Ann Intern Med 1998; 128: 657-662.

7. Nishi J, Maruyama I. Increased expression of vascular endothelial growth factor (VEGF) in Castleman's disease: proposed pathomechanism of vascular proliferation in the affected lymph node. Leuk Lymphoma 2000; 38: 387-394.

8. Winter SS, Howard TA, Ritchey AK, Keller FG, Ware RE. Elevated levels of tumor necrosis factor-beta, gammainterferon, and IL-6 mRNA in Castleman's disease. Med Pediatr Oncol 1996; 26: 48-53.

9. Eddahibi S, Humbert $\mathrm{M}$, Sediame $\mathrm{S}$, et al. Imbalance between platelet vascular endothelial growth factor and platelet-derived growth factor in pulmonary hypertension. Effect of prostacyclin therapy. Am J Respir Crit Care Med 2000; 162: 1493-1499.

10. Voelkel NF, Hoeper M, Maloney J, Tuder RM. Vascular endothelial growth factor in pulmonary hypertension. Ann NY Acad Sci 1996; 796: 186-193.

11. Belec L, Mohamed AS, Authier FJ, et al. Human herpesvirus 8 infection in patients with POEMS syndrome-associated multicentric Castleman's disease. Blood 1999; 93: 3643-3653.

12. Pellicelli AM, Barbaro G, Palmieri F, et al. Primary pulmonary hypertension in HIV patients: a systematic review. Angiology 2001; 52: 31-41.

13. Seoane L, Shellito J, Welsh D, de Boisblanc BP. Pulmonary hypertension associated with HIV infection. South Med J 2001; 94: 635-639.

14. Bardwick PA, Zvaifler NJ, Gill GN, Newman D, Greenway GD, Resnick DL. Plasma cell dyscrasia with polyneuropathy, organomegaly, endocrinopathy, $\mathrm{M}$ protein, and skin changes: the POEMS syndrome. Report on two cases and a review of the literature. Medicine (Baltimore) 1980; 59: 311322.

15. Izawa T, Fukata $\mathrm{Y}$, Kimura $\mathrm{T}$, Iwamatsu A, Dohi $\mathrm{K}$, Kaibuchi K. Elongation factor-1alpha is a novel substrate of rho-associated kinase. Biochem Biophys Res Commun 2000; 278: 72-78.

16. Lesprit $\mathrm{P}$, Godeau B, Authier FJ, et al. Pulmonary hypertension in POEMS syndrome: a new feature mediated by cytokines. Am J Respir Crit Care Med 1998; 157: 907911.

17. Pan L, Milligan L, Michaeli J, Cesarman E, Knowles DM. Polymerase chain reaction detection of Kaposi's sarcomaassociated herpesvirus-optimized protocols and their application to myeloma. J Mol Diagn 2001; 3: 32-38.

18. White IE, Campbell TB. Quantitation of cell-free and cellassociated Kaposi's sarcoma-associated herpesvirus DNA by real-time PCR. J Clin Microbiol 2000; 38: 1992-1995.

19. Simpson GR, Schulz TF, Whitby D, et al. Prevelence of Kaposi's sarcoma assoicated herpesvirus infection measured by antibodies to recombinant capsid protein and latent immunofluorescence antigen. Lancet 1996; 348: 1133-1138.

20. Ensoli B, Sgadari C, Barillari G, Sirianni MC, Sturzl M, Monini P. Biology of Kaposi's sarcoma. Eur J Cancer 2001; 37: 1251-1269.

21. Casper C, Krantz E, Taylor H, et al. Assessment of a combined testing strategy for detection of antibodies to human herpesvirus 8 (HHV-8) in persons with Kaposi's sarcoma, persons with asymptomatic HHV-8 infection, and persons at low risk for HHV-8 infection. $J$ Clin Microbiol 2002; 40: 3822-3825.

22. Tedeschi R, Dillner J, De Paoli P. Laboratory diagnosis of human herpesvirus 8 infection in humans. Eur $J$ Clin Microbiol Infect Dis 2002; 21: 831-844. 